\title{
Unruptured Scissural Pleural Primitive Hydatid Cyst an Unusual Presentation of Intrathoracic Hydatic Cyst: A Case Report
}

\author{
Doumbia $\mathrm{M}^{1,2^{*}}$, Kone $\mathrm{S}^{1}$, Diatta $\mathrm{S}^{1}$, Dara $\mathrm{C}^{1}$, Diarra $\mathrm{BI}^{1}$, Sawadogo $\mathrm{A}^{3}$, Banga Nkomo $\mathrm{DD}^{3}$, Maïga $\mathrm{AA}^{1}$, \\ Sidibe $S^{2}$, Mariko $M^{2}$, Ndiaye $A^{3}$ and Ndiaye $M^{3}$ \\ ${ }^{1}$ Pneumology Department, University Hospital of Fann, Dakar, Senegal \\ ${ }^{2}$ Cardiothoracic and Vascular Surgeon, Center Cardiopediatric Andre Festoc, Mali \\ ${ }^{3}$ Department of thoracic and cardiovascular surgery, University Hospital of Fann, Dakar, Senegal
}

"Corresponding author: Modibo Doumbia, MD, Cardiothoracic and Vascular Surgeon, Center Cardiopediatric Andre Festoc, Mali, Tel: +221 3382519 30; E-mail: modibodoumbia25@yahoo.fr

Received: April 15, 2019; Accepted: April 23, 2019; Published: April 29, 2019

\begin{abstract}
Pleural hydatidosis is usually secondary to a rupture of a hydatid cyst of the lung or liver into pleura. The primitive, isolated and unruptured pleural form is rare. We report a case of a woman, living in an endemic area for hydatidosis, diagnosed with an isolated, unruptured, scissural pleural primitive hydatid cyst which looks like mass on lung imaging. This case emphasizes that, isolated, unruptured, scissural pleural primitive hydatid cyst can be mistaken for a lung mass and that surgery remains both a useful diagnostic and therapeutic approach to its management.
\end{abstract}

Keywords: Primitive hydatid cyst; Scissural pleural; Surgery

\section{Introduction}

Hydatidosis is due to the development in humans of Echinococcus granulosus larva [1]. Hepatic localization is the most common (50\%-70\%), followed by pulmonary localization (25\%-40\%). Pleural localization is usually secondary to rupture of a pulmonary or hepatic hydatid cyst. Primitive pleural site is rare, accounting for only $1.3 \%$ of the thoracic site [2-4], and unruptured, scissural pleural primitive hydatid cyst are even fewer. This unusual location can be mistaken for a lung mass.

\section{Case Report}

A 42-year-old housewife permanently residing in Mauritania for 10 years, an endemic area for hydatidosis, with suspicion of contact with dogs, with no relevant past medical history, consulted for symptoms evolving for 6 months.

Citation: Doumbia M, Kone S, Diatta S, et al. Unruptured Scissural Pleural Primitive Hydatid Cyst an Unusual Presentation of Intrathoracic Hydatic Cyst: A Case Report. Clin Case Rep Open Access. 2019;2(2):125.

(C)2019 Yumed Text. 
She complains of a dry cough, aggravated by movements of upper limb; persistent and constant upper right chest pain, exacerbated by cough, not relieved by usual analgesics and stage II dyspnea of Modified Medical Research Council. She did not report fever and her general status was preserved.

On clinical examination we noticed a pleural fluid effusion syndrome in the upper half of the right hemithorax. The chest xray showed a well marginated rounded, homogeneous, opacity occupying the upper right hemithorax measuring more than 3 cm (FIG. 1).

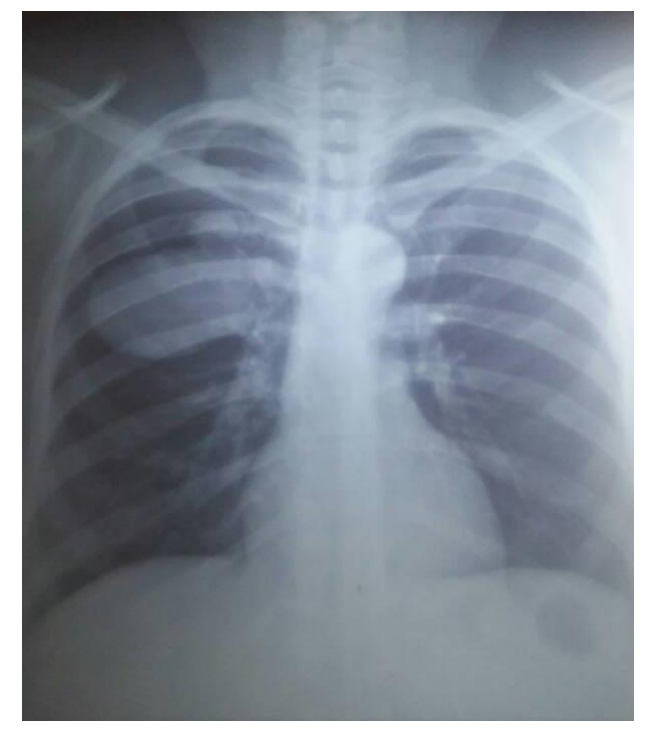

FIG. 1. Chest x-ray showed a well marginated rounded, homogeneous, opacity occupying the upper right hemithorax.

Thoracic CT scan showed an isolated hyperdense mass, without calcification, an average maximum diameter of $8 \mathrm{~cm}$, localized on the small fissure, surrounded by normal parenchyma of superior and inferior lobes of right lung (FIG. 2). The abdominal ultrasound was normal. The hydatid serologies (ELISA and Indirect Agglutination) were negative.

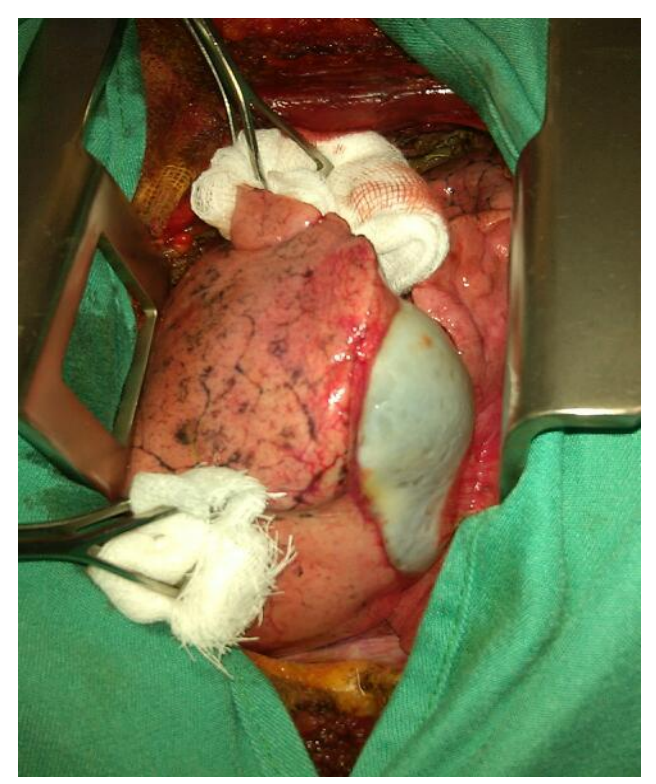

FIG. 2. Operative view of pleural cyst localized in the small fissure. 
A decision of surgical removal, by thoracotomy, of a symptomatic indeterminate intrathoracic mass was taken.

The exploration showeds an unruptured, pleural cyst localized in the small fissure, measuring approximately $15 \mathrm{~cm} \times 15 \mathrm{~cm}$, without pulmonary involvement. We then performed a cystectomy using the Barrett technique. Postoperative chest $\mathrm{X}$ ray was normal (FIG. 3).

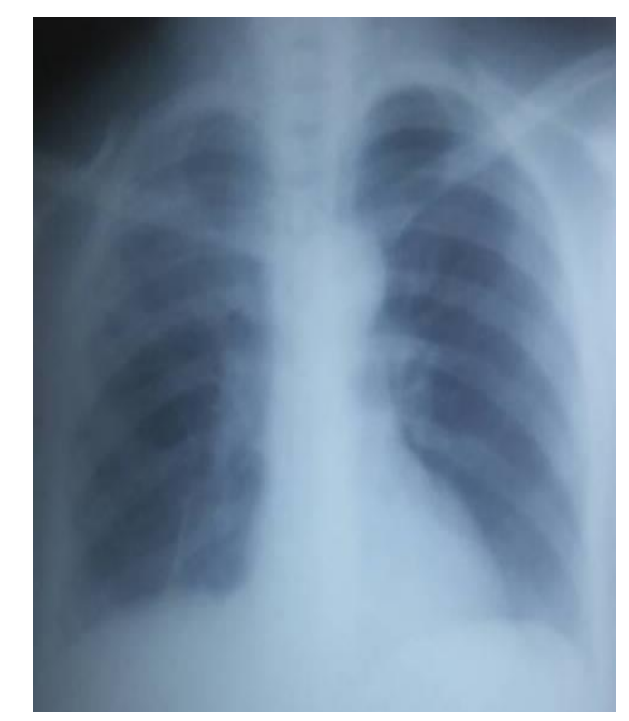

FIG. 3. Normal post-operative chest $\mathrm{X}$ ray of the patient.

Post-operative histological study of the cyst showed a fibrous adventitia. On that adventitia, there was a proliferous membrane with multiple parasitic larvae and some protoscolex on the endocystic surface.

Then, the diagnosis of pleural primitive hydatid cyst type II of Gharbi classification was retrospectively made. The patient was put on Albendazole for 6 months.

\section{Discussion}

Hydatidosis is an anthropozoonosis caused by Echinococcus granulosus. It is a real scourge for livestock and a major public health problem commonly encountered around Mediterranean than in sub-Saharan pastoral areas such as Mauritania where it is present in almost all slaughterhouses [1,5].

The normal life cycle of the parasite involves two hosts: an intermediate host for the larval form (an herbivore) and a definitive host for the adult form (a carnivore). The definitive host becomes infected by devouring the intermediate host or by devouring only the viscera carrying cysts [2].

Mammal including Human can be accidental intermediate when there is close contact with dogs (caresses, licking by the dog) or when they ingest contaminated vegetables, fruits or water. 
www.yumedtext.com | April-2019

The Pleural localization is usually secondary. However, primitive pleural localization has been reported and represents only about $1.3 \%$ of thoracic location [2,4]. When the patient has no other hepatic, pulmonary or splenic localization like our patient the pleural contamination could be due to blood contamination. The latter presented with a nonspecific and discrete clinical symptomatology, consistent with that reported in the literature in primitive pleural localizations $[4,6]$.

Chest imaging, in a suggestive epidemiological context, is an invaluable contribution to the diagnosis of hydatidosis [7,8]. It can show a homogeneous pleural opacity, well-defined with water tonality.

In our patient, as the thorax CT scan showed a hyperdense mass surrounded by normal parenchyma of superior and inferior lobes of right lung we cannot conclude could not make a diagnostic to primitive pleural hydatid cyst. Nevertheless, the suggestive epidemiological context does not allow the puncture as this one is contraindicated in case of hydatid cyst. And, as immunological tests and blood count cells are of little value for the diagnosis of hydatid cyst, especially for unruptured forms [9], the surgery became a diagnostic and therapeutic means.

Indeed the diagnostic of certitude in some case like ours can be operative by visualizing the typical aspect of hydatid membrane. Postoperative histological study of the resected cyst confirms the diagnostic.

\section{Conclusion}

The primitive pleural location of the hydatid cyst is uncommon, and unruptured, scissural pleural primitive hydatid cyst are even fewer. It can be confused with a lung mass. In that condition, surgery remains both useful diagnostic and therapeutic means.

\section{Conflicts of Interest}

The authors do not report conflicts of interest

\section{REFERENCES}

1. Bronstein JA, Klotz F. Larval tapeworms infections. EMC Maladies Infectieuses. 2005;2(2):59-83.

2. Harzallah L, Bacha M, Garrouche A, et al. Primitive pleural hydatid cyst: about an observation. Rev Med Liege. 2007;62 (7-8 ):506-8.

3. Bouhaouala MH, Hendaoui L, Charfi MR, et al. Thoracic hydatidosis. EMC, Radiodiagnostic-Heart-Lung. 32-470A-20. 2007.

4. Thameur H, Chenik S, Abdelmoulahet S, al. The thoracic locations of hydatidosis. Rev Pneumo clin. 2000;56(1):715.

5. Ould Ahmed Salem CB, Schneegans F, Chollet JY, et al. Prevalence and lesional aspects of hydatidosis in dromedaries and small ruminants in northern Mauritania. Revue Élev Méd vét Pays trop. 2010;63(1-2):23-8.

6. Redington AE, Russell SG, Ladhani S, et al. Pulmonary echinococcosis with chest wall involvement in a patient with no apparent risk factors. J Infect. 2001;42(4):285-8.

7. Hafsa B, Belguith M, Golli M, et al. Imaging of pulmonary hydatid cyst in children. J Radiol. 2005;86(4):405-10. 
www.yumedtext.com | April-2019

8. Gharbi HA, Ben Chehida F, Bardi I, et al. Parasitic pulmonary diseases. Technical editions. - Encycl Med Chir. (Paris-France). Radiodiagnostic-Heart-Lung. 32-470-A-10. 1993. 28 p.

9. El Biaze M, et al. Thoracic hydatidosis: news and developments. Rev Mal Resp. 2006;23(4):80-2. 